\title{
Preliminary results from a continuous record of atmospheric gaseous mercury at the coastal station Dumont d'Urville in Antarctica
}

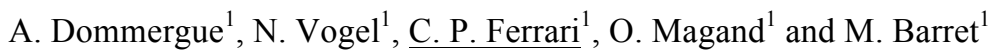 \\ ${ }^{1}$ UJF - Grenoble 1 / CNRS, Laboratoire de Glaciologie et Géophysique de l'Environnement (LGGE) UMR 5183, \\ Grenoble, F-38041, France dommergue@lgge.obs.ujf-grenoble.fr
}

\begin{abstract}
While the tropospheric reactivity of mercury $(\mathrm{Hg})$ in the Arctic is more and more documented only a few attempts were made to study the $\mathrm{Hg}$ cycle in the Southern Polar Regions. The role of the Antarctic continent and its influence on the global geochemical cycle of mercury is unclear today, and is certainly under evaluated by current models. Here, we present the first continuous high-time-resolution measurements of atmospheric gaseous elemental mercury (GEM) in East Antarctica from February 2010 to March 2011 at the coastal research station Dumont d'Urville (DDU) (66 $46^{\circ}$ 'S, $140^{\circ} 01^{\prime} \mathrm{E}, 43 \mathrm{~m}$ asl). We report an annual mean level of $1.062 \pm 0.321 \mathrm{ng} / \mathrm{m}^{3}$ with well-marked daily fluctuations from October to January. An intense reactivity originated from the atmospheric boundary layer of the Antarctic plateau under sunlight conditions is observed at DDU. Partly GEM-depleted air masses are exported from the continent and dramatically influence the GEM record at DDU. From November to January, surface waters of the Southern Ocean are an important source of GEM.
\end{abstract}

Key words: Atmospheric gaseous elemental mercury, Antarctica, Seasonal cycle, GMOS

\section{Introduction}

Polar Regions, like other regions of the planet, are impacted by long-range transport of man-made emissions of mercury $(\mathrm{Hg}) . \mathrm{Hg}$ is mostly transported as Gaseous Elemental Mercury (GEM), which has a lifetime of about 1 year in the troposphere. In Antarctica, gross $\mathrm{Hg}$ input is probably controlled by Southern Hemisphere emissions.

The tropospheric reactivity of $\mathrm{Hg}$ in the Arctic is more and more documented (Steffen et al., 2008) due to the occurrence of springtime fast GEM oxidation processes called Atmospheric Mercury Depletion Events (AMDE). In the Southern Polar Regions, only a few attempts were made to study the $\mathrm{Hg}$ cycle. Observations retrieved from central Antarctica (elevation $>2500 \mathrm{~m}$, coldest place of the Earth with long polar nights) and coastal stations are distinctly different (for a review see Dommergue et al., 2010).

AMDE have been observed at the coastal sites of Neumayer, Terra Nova Bay and McMurdo (Brooks et al., 2008b, Ebinghaus et al., 2002, Sprovieri et al., 2002) after polar sunrise (around the beginning of August). AMDE such as observations in the Arctic are correlated to ozone $\left(\mathrm{O}_{3}\right)$ depletions and marine/sea-ice air masses that are suspected to be enriched in reactive halogens.
The oxidation of GEM during AMDE lead to the formation and deposition of divalent mercury as observed at McMurdo (Brooks et al., 2008b). During the austral summer (November to February), atmospheric oxidized $\mathrm{Hg}$ species have surprisingly been measured in the absence of simultaneous GEM and $\mathrm{O}_{3}$ depletions at Terra Nova and Neumayer (Sprovieri et al., 2002, Temme et al., 2003). GEM and $\mathrm{O}_{3}$ could be negatively correlated suggesting different chemical processes that could be influenced by chemistry occurring on the Antarctic Plateau as suggested by Temme et al. (2003).

High concentrations of atmospheric oxidized mercury were measured over the plateau in summer too (Brooks et al., 2008a). According to numerical models, atmospheric subsidence events may bring to the Antarctic boundary layer low GEM levels and oxidized species of mercury due to bromine chemistry in the upper troposphere (Holmes et al., 2006). A recent study carried out at Dome Concordia on the Antarctic Plateau in January (Dommergue et al., 2012) has shown that GEM was negatively correlated to $\mathrm{O}_{3}$ and followed high day-to-day fluctuations. GEM maxima were observed in early afternoon and very low levels (under detection limits) during low irradiation periods. It suggests that the Plateau could be a highly oxidizing place for GEM.

We report here GEM measurements from a monitoring campaign at Dumont d'Urville (DDU) in East 
Coastal Antarctica from February 2010 to March 2011. The site is a relevant place to study the biogeochemical cycle of atmospheric Hg. DDU is both influenced by marine air masses and continental air masses from the Antarctic plateau transported by powerful katabatic winds. DDU is an opportunity to concomitantly study marine sources of $\mathrm{Hg}$ and to observe the transport of reactive air masses from the plateau.

\section{Materials and Methods}

From February 12, 2010 to March 5, 2011, highly time-resolved measurements of GEM were carried out at the French polar station Dumont d'Urville (East Antarctica, $66^{\circ} 40^{\prime} \mathrm{S}, 140^{\circ} 01^{\prime} \mathrm{E}, 43 \mathrm{~m}$ above sea level). The base is located on the Archipel Pointe Géologie about $1 \mathrm{~km}$ north of the coastline of Adélie land.

A Tekran 2537A gas-phase mercury vapor analyzer was used for the determination of atmospheric GEM. The pre-filtered air stream (soda lime trap and $0.2 \mu \mathrm{m}$ Teflon particles filter) is alternatively collected on two gold cartridges. GEM is then thermally desorbed and detected by cold vapor atomic fluorescence spectrometry at 253.7 $\mathrm{nm}$. Dual gold cartridges allow alternate sampling and desorption, resulting in continuous measurements of GEM on a 5 minutes time step. At DDU, the air was sampled at a flow rate of $1.5 \mathrm{~L} / \mathrm{min}$. The analyzer was calibrated every $24 \mathrm{~h}$ using an internal automatic permeation source injection. This permeation source was recalibrated by manual injections of GEM vapor using a micro-syringe.

\section{Results and Discussion}

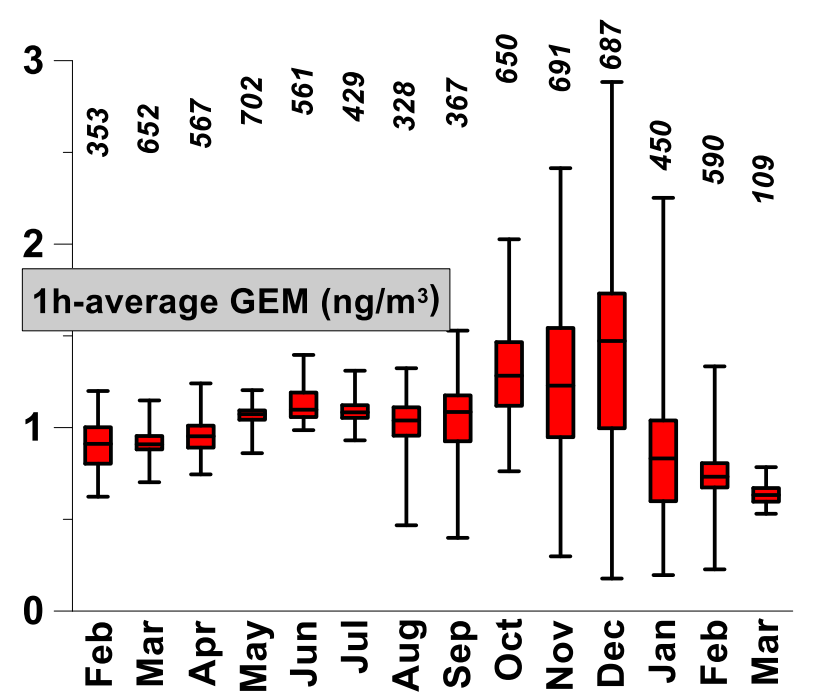

Fig. 1. Whisker plot of monthly 1 h-average GEM data from Feb 2010 to March 2011. Minimum, 25 ${ }^{\text {th }}$, median, $75^{\text {th }}$ and maximal values are displayed. $\mathrm{N}$ is shown at the top of the figure box.

As observed in Fig.1, the data set shows two distinct periods. (1) From March to July, GEM concentrations remain fairly constant with a mean value around $1.027 \pm$ $0.107 \mathrm{ng} / \mathrm{m}^{3}$ (median of $1.046 \mathrm{ng} / \mathrm{m}^{3}$ ). Daily variations are hardly observed. (2) From August to February, GEM levels are highly variable (mean of $1.086 \pm 0.401 \mathrm{ng} / \mathrm{m}^{3}$ and median of $1.078 \mathrm{ng} / \mathrm{m}^{3}$ ) with a maximal dynamic in December. A diurnal cycle is often observed with minimum concentration during the night $(\mathrm{GEM}<1$ $\left.\mathrm{ng} / \mathrm{m}^{3}\right)$. GEM levels often rise above $1.5 \mathrm{ng} / \mathrm{m}^{3}$ during afternoons.

We split our data set into two periods: winter (April to September) and summer (October to March). The choice is made to be consistent with the solar radiation cycle on the plateau. Using HYSPLIT calculations (Draxler and Rolph, 2003), we split our data set according to the synoptic-scale origins of air masses. "Ocean" and "Plateau" air masses were attributed to air masses that have travelled over the ocean and the continent for full 5 days respectively.

\section{Oceanic Influence}

As shown on Fig.2, the summer distribution of marine air masses looks bimodal. Looking at elevated GEM data ( $>$ $1.3 \mathrm{ng} / \mathrm{m}^{3}$ ), the Austral Ocean seems to be a source of $\mathrm{Hg}(0)$ from November to mid-January. We suggest that the local marine biological productivity and thus large production of GEM via reduction of $\mathrm{Hg}$ (II) may occur. Cossa et al. (2011) showed high total Hg concentration in under-ice seawater in the vicinity of DDU. Sea-ice is known to act as a barrier for mercury exchange between the ocean and the atmosphere (Andersson et al., 2008). The total collapsing of the sea-ice around DDU occurred on 10 November 2010 leading to large emissions of GEM.

The analysis of GEM levels with respect to sea ice extent (not shown) show that oceanic concentrations below $1.3 \mathrm{ng} / \mathrm{m}^{3}$ occur after a transport over a sea ice cover of at least $60 \%$. Air masses from the Ross Sea (East of DDU) are characteristic of these low levels that may be explained by reactivity with halogens.

A different pattern is observed on the winter distribution (Fig. 2). With the exception of some low levels below $0.6 \mathrm{ng} / \mathrm{m}^{3}$ (explained by AMDE, not discussed here), winter concentrations are rather a signature of Southern Hemisphere background levels. The austral marine atmospheric boundary layer is either a source or a sink (via halogen oxidation processes) during wintertime. The high stability (low standard deviation) confirms that frozen sea do not influence much GEM levels at DDU during winter months.

\section{The key role of the Antarctic Plateau}

As shown on Fig. 3, 90\% of the time, GEM measured during winter is influenced by continental flows. Very low standard deviations suggest a weak GEM reactivity on the continent during the dark period. We assume a winter plateau background level in the range of 0.9 to 1.1 $\mathrm{ng} / \mathrm{m}^{3}$ (at a 95\% confidence level) with poor daily variations. These levels are in the range of winter Southern Hemisphere background concentrations (Brunke et al., 2010).

Plateau air masses are characterized by important dynamics in GEM records during the summer. This 
indicates an intense reactivity on the continent. A well-marked daily cycle of GEM is observed at DDU from mid-November to the end of January when the sunlight is permanent on the plateau. During this period very low levels (below $0.5 \mathrm{ng} / \mathrm{m}^{3}$ ) are observed at night and concentration often rises above $1.5 \mathrm{ng} / \mathrm{m}^{3}$ in mid-afternoon (16:00). In addition, GEM and ozone show a negative correlation which is not the case during winter. The same patterns have been previously observed at Dome Concordia (Dommergue et al., 2012) in January 2009. Although it is not clear yet, they propose a fast oxidation by an unknown oxidant in a confined boundary layer during low irradiation. A dilution with a free troposphere, enriched in GEM, happens during higher irradiance, associated with photoreduction of deposited mercury on the snow surface. We assume an export of this signal to coastal Antarctica which may end at the beginning of February.
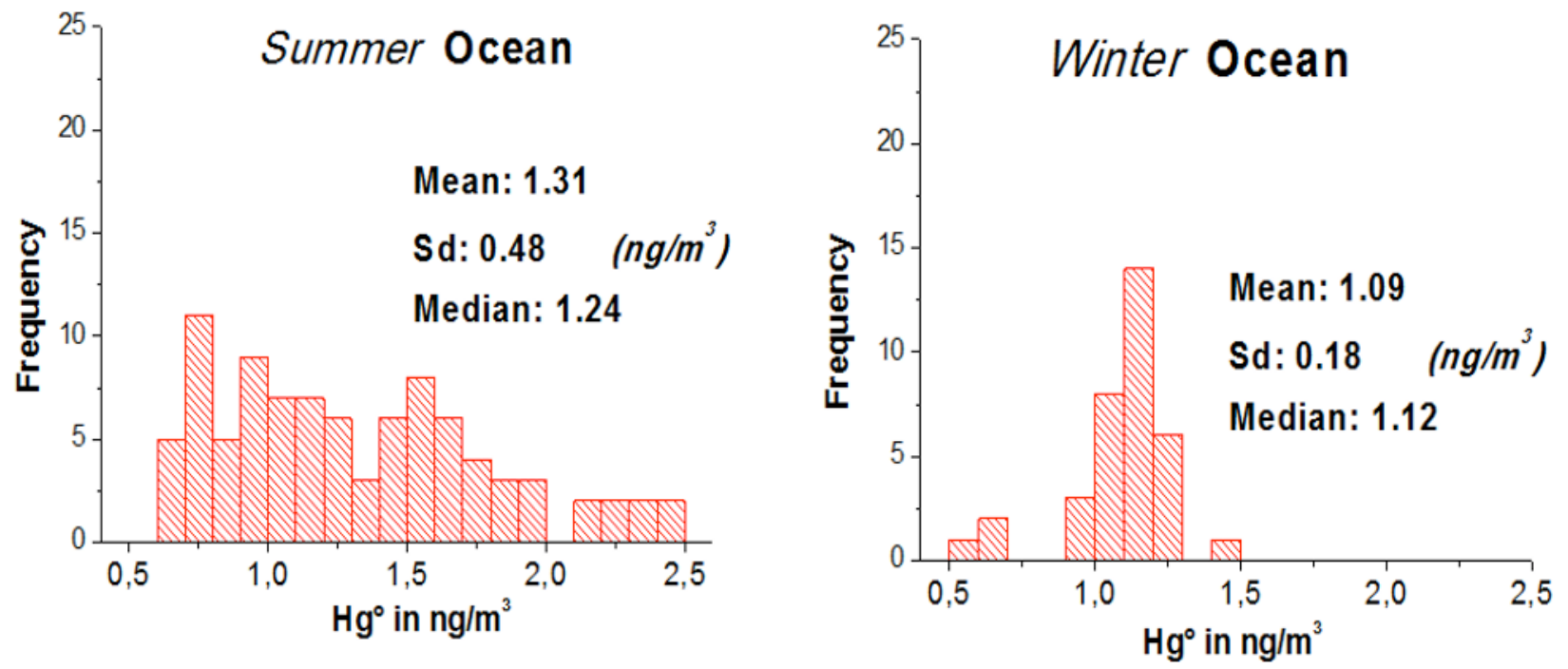

Fig. 2 Distribution of summer and winter 6h-average GEM for marine air masses.
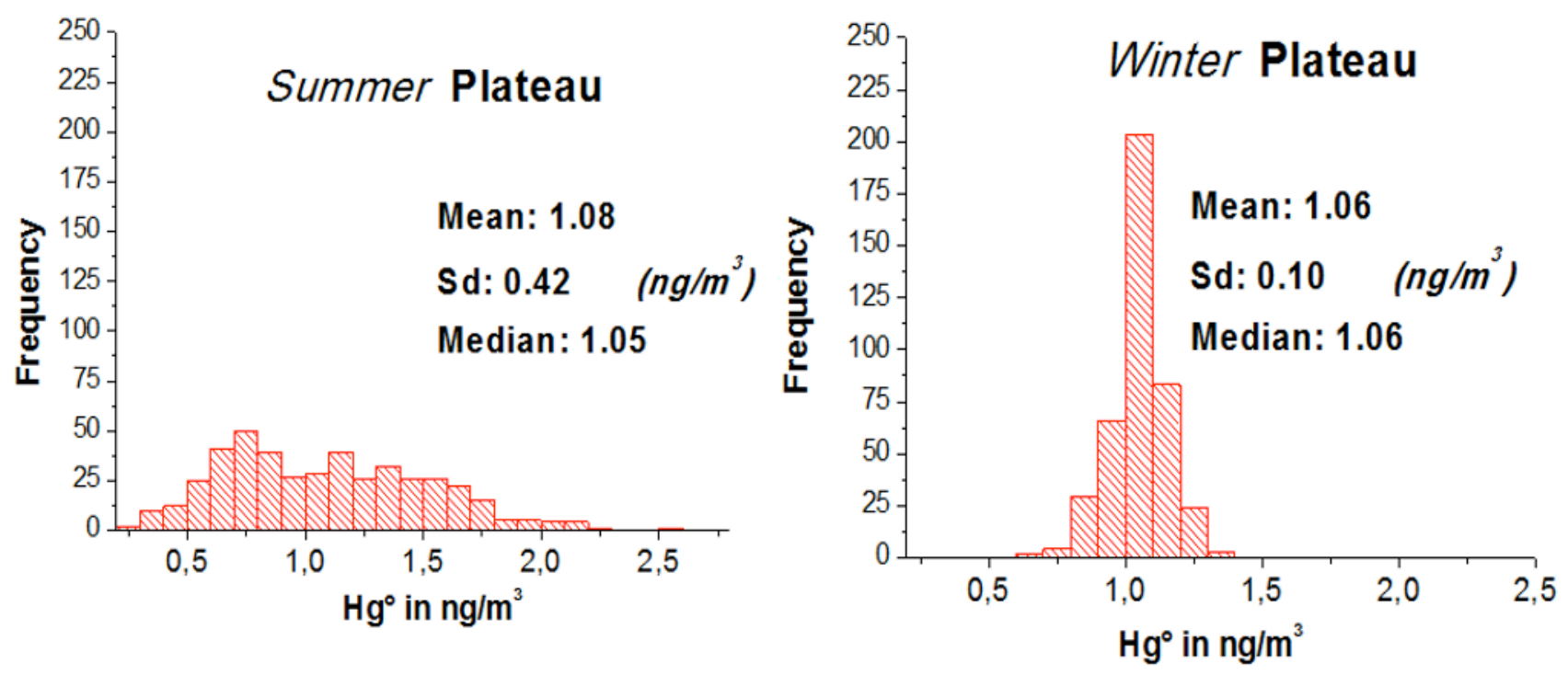

Fig. 3 Distribution of summer and winter 6h-average GEM for air masses from the Antarctic Plateau.

\section{Conclusion}

This first year of monitoring at DDU brings new insights into the role of both the Austral Ocean and the Antarctic Plateau on coastal GEM records in Antarctica. The high stability of GEM measured during fall and winter is mainly explained by an export of continental air masses. Under dark condition, we assume that a weak reactivity with poor daily variations of GEM exist on the Antarctic Plateau. Although the rare oceanic events show slightly higher concentration $\left(1.1 \mathrm{ng} / \mathrm{m}^{3}\right)$, the marine boundary layer exhibits higher oxidizing capacity during the winter. From October to January, GEM is generally negatively correlated to ozone and follows high daily fluctuations. Strong decreases of GEM are observed 
during low irradiation and high levels (above 1.5 $\mathrm{ng} / \mathrm{m} 3$ ) during afternoon. The intense reactivity on the Antarctic Plateau under sunlight condition could be exported to DDU. Following recent studies of Cossa et al. (2011), we identified an important source of GEM from the Austral Ocean from November to January. Due to the different and well-marked air masses origins, DDU appears to be a very useful place to study the southern hemisphere GEM background, the Antarctic plateau GEM background (during winter time), and the contribution of the Antarctic plateau reactivity during summer months.

\section{Acknowledgements}

This work contributes to the EU-FP7 project Global Mercury Observation System (GMOS). Logistical support and financial support were also provided by the French Polar Institute IPEV (Program 1028, GMOStral). $\mathrm{AD}$ is grateful to the Institut Universitaire de France. We want to acknowledge CHIMIE-ORE CESOA and the winterovering technical staff (Nicolas Coillard).

\section{References}

Andersson ME, Sommar J, Gardfeldt K, Lindqvist O. Enhanced concentrations of dissolved gaseous mercury in the surface waters of the Arctic Ocean. Mar. Chem. 2008;110:190-194.

Brooks S, Arimoto R, Lindberg S, Southworth G. Antarctic polar plateau snow surface conversion of deposited oxidized mercury to gaseous elemental mercury with fractional long-term burial. Atmos. Environ. 2008a;42:2877-2884.

Brooks S, Lindberg S, Southworth G, Arimoto R. Springtime atmospheric mercury speciation in the McMurdo, Antarctica coastal region. Atmos. Environ. 2008b;42:2885-2893.

Brunke EG, Labuschagne C, Ebinghaus R, Kock HH, Slemr F. Gaseous elemental mercury depletion events observed at Cape Point during 2007-2008. Atmos. Chem. Phys. 2010;10:1121-1131.

Cossa D, Heimburger LE, Lannuzel D, Rintoul SR, Butler ECV, Bowie AR, Averty B, Watson RJ,
Remenyi T. Mercury in the Southern Ocean. Geochim. Cosmochim. Acta 2011;75:4037-4052.

Dommergue A, Barret M, Courteaud J, Ferrari CP, Cristofanelli P. Dynamic cycling of $\mathrm{Hg}(0)$ inside the Antarctic Plateau boundary layer. submitted to Atmospheric Chemistry and Physics Discussions 2012.

Dommergue A, Sprovieri F, Pirrone N, Ebinghaus R, Brooks S, Courteaud J, Ferrari CP. Overview of mercury measurements in the Antarctic troposphere. Atmos. Chem. Phys. 2010;10:3309-3319.

Draxler RR, Rolph GD. HYSPLIT (HYbrid Single-Particle Lagrangian Integrated Trajectory) Model access via NOAA ARL READY Website (http://www.arl.noaa.gov/ready/hysplit4.html).

NOAA Air Resources Laboratory, Silver Spring, MD. 2003;

Ebinghaus R, Kock HH, Temme C, Einax JW, Löwe AG, Richter A, Burrows JP, Schroeder WH. Antarctic Springtime Depletion of Atmospheric Mercury. Environ. Sci. Technol. 2002;36:1238 -1244.

Holmes CD, Jacob DJ, Yang X. Global lifetime of elemental mercury against oxidation by atomic bromine in the free troposphere. Geophys. Res. Lett. 2006;33:L20808.

Sprovieri F, Pirrone N, Hedgecock IM, Landis MS, Stevens RK. Intensive atmospheric mercury measurements at Terra Nova Bay in Antarctica during November and December 2000. J. Geophys. Res. 2002;107:4722.

Steffen A, Douglas T, Amyot M, Ariya P, Aspmo K, Berg T, Bottenheim J, Brooks S, Cobbett F, Dastoor A, Dommergue A, Ebinghaus R, Ferrari C, Gardfeldt K, Goodsite ME, Lean D, Poulain AJ, Scherz C, Skov H, Sommar J, Temme C. A synthesis of atmospheric mercury depletion event chemistry in the atmosphere and snow. Atmos. Chem. Phys. 2008;8:1445-1482.

Temme C, Einax JW, Ebinghaus R, Schroeder WH. Measurements of Atmospheric Mercury Species at a Coastal Site in the Antarctic and over the South Atlantic Ocean during Polar Summer. Environ. Sci. Technol. 2003; 37:22-31. 